Notre Dame Journal of Formal Logic

Volume 40, Number 1, Winter 1999

\title{
Logic and the Discursive Intellect
}

\author{
PENELOPE MADDY
}

\begin{abstract}
The effort to fit simple logical truths-like 'if it's either red or green and it's not red, then it must be green'-into Kant's account of knowledge turns up a position more subtle and intriguing than might be expected at first glance.
\end{abstract}

1 Introduction My aim in this paper is to sketch a tentative reading of Kant's philosophy of logic. As logic was not the focus of his critical inquiry, we should not be surprised to find Kant less explicit on the subject than we might like, which makes sharp conclusions about his views even more elusive here than in the rest of his philosophy. Another impediment is my own strictly amateur status in the subtle and demanding art of Kant interpretation. Perhaps the view to be proposed will be suggestive or provocative enough to retain some interest even if it cannot ultimately be defended as a responsible reading of Kant himself.

When I speak of logic or logical truth, I have in mind simple, uncontroversial examples like:

If all oaks are trees, and this is an oak, then this must be a tree.

or

If it's either red or green, and it's not red, then it must be green.

or particular instances of modus ponens or modus tollens. By 'philosophy of logic', I mean the simple metaphysical and epistemological questions that arise at the very beginning of any 'philosophy of $x$ ': What kind of truths are these? How do we know them? In the case of logic, there is also the special problem of determining the source of the logical 'must'.

In some sweet future, I hope for answers to these questions in their full generality, but for now, my central goal is to understand how Kant might have answered them. To this end, I propose to trace two lines of approach to a Kantian account of logic, eventually converging on a view that I hope is reasonably Kantian in spirit. At the end, I'll allow myself some brief, vague, and inconclusive speculations on how this account might be adapted to the purposes of a contemporary naturalist.

Received April 16, 1998 
2 Analytic a priori We're asking about the status of a claim such as 'if it's either red or green and it's not red, then it must be green'; we want to know what kind of truth it expresses and how humans come to know that truth. Kant provides us with a simple taxonomy of possible answers: truths are analytic or synthetic; we can know them a priori or a posteriori. Of these, analytic a priori seems the obvious choice, so it seems reasonable to begin by asking if this obvious choice can be made sense of.

Before turning attention to this question, I should report an oddity: I haven't been able to find a place where Kant explicitly says that $\operatorname{logic}^{1}$ is analytic. He tells us often enough that it is a priori (e.g., A53/B77, A54/B78, A131/B170, [13, p. 15, [11, p. 693), but the only remotely logical claim that he explicitly classifies as analytic is $A=A$ (B16-17) and this hardly lies at the core of what Kant considers logic. ${ }^{2}$ On the other hand, I don't mean to suggest that Kant held logic to be synthetic; for now, I only note the anomaly. ${ }^{3}$

Leaving this aside, our question is: How might logic be made out to be analytic a priori? Of course, Kant's notion of analyticity is a study in itself, but for our purposes, I think it is enough to work from the familiar 'containment' analysis:

In all judgments in which the relation of a subject to the predicate is thought . . . this relation is possible in two different ways. Either the predicate $B$ belongs to the subject $\mathrm{A}$, as something which is (covertly) contained in this concept $\mathrm{A}$; or B lies outside the concept A... . In the one case I entitle the judgment analytic, in the other synthetic. (A6/B10)

A concept, for Kant, "refers . . . by means of a feature [or features] which several things may have in common" (A320/B377). An analytic judgment is one whose predicate is one of the features already present in the concept of the subject (A7/B11-2): for example, 'extension' is one of the features of the concept 'body' (along with 'figure', 'impenetrability', etc.) so 'all bodies are extended' is analytic; 'heavy' is not a feature of the concept 'body', so 'all bodies are heavy' is synthetic. ${ }^{4}$ To cite a more familiar, and perhaps more congenial example, 'bachelors are unmarried' comes out analytic, as we'd expect.

Of course, by itself, the containment analysis is of no use to us, because our sample logical truths are not of subject/predicate form; indeed their complex logical forms seem, pretheoretically, to be the source of their logical truth. So, let's adopt the obvious strategy for extending the containment analysis and take a judgment to be analytic if and only if its truth depends only on the concepts involved. As a special case, we add that an analytic truth is logical if its truth depends only on the logical concepts involved (that is: all, some, is, is not, if/then, or, and, and so on). On this account, 'bachelors are unmarried' and 'nothing is both crimson and not red' would come out analytic, but not logical, and all our samples would come out both analytic and logical: the truth of 'if it's either red or green and it's not red, then it must be green' depends only on the concepts 'if/then', 'or', and 'not'. On this view, we can see the direction one might take in answering our metaphysical questions: logical truth would be conceptual, and the force of the logical must would come from the rigidity of the logical concepts.

Turning to epistemology, we then ask how humans can know the logical truths expressed in our examples, and in particular, how we can know them to be logically necessary, which comes to asking how humans can know that analytic truths are true 
and that they are analytic. In other words, we wonder how we can know that the truth of our examples is 'contained in' the logical concepts involved.

Much could be said about Kant's thinking on the question of how we know what is or isn't contained in a concept (e.g., see Beck [4]), but for our purposes, the salient point is that the answer and its significance varies depending on the type of concept involved. First and most familiar are the empirical given concepts, which include ordinary notions like 'water' and 'gold'. These, Kant thinks, "cannot be defined at all” (A727/B755), because, for example:

in the concept gold one man may think, in addition to its weight, colour, malleability, also its property of resisting rust, while another will perhaps know nothing of this quality. (A728/B756)

But this lack of a sharp definition doesn't trouble him:

indeed what useful purpose could be served by defining an empirical concept, such, for instance, as that of water? When we speak of water and its properties, we do not stop short at what is thought in the word, water, but proceed to experiments. The word, with the few characteristics which we attach to it, is more properly to be regarded as merely a designation than as a concept of the thing; the so-called definition is nothing more than a determining of the word. (A728/B756)

We can define and redefine the concept 'water' as we go along, in the interests of clarity, but we are really just fixing our use of the word 'water', and we should not let these temporary, pragmatic definitions impede the course of our scientific inquiries ("water cannot be $\mathrm{H}_{2} 0$; it's defined to be a simple substance!"). Thus it seems Kant would hardly be surprised or bothered by the observation that the classification of various judgments about water as analytic or synthetic might shift as science progresses.

In contrast to empirical given concepts like 'water' and 'gold' - the sort of thing we might call natural kind concepts - there are concepts like 'bachelor' and 'keyboard' which we make up; Kant calls these empirical constructed concepts. Such concepts are easily definable:

A concept which I have invented I can always define; for since it is not given to me . . . by experience, but is such as I have myself deliberately made it to be, I must know what I have intended to think in using it. (A727/B757)

Constructed empirical concepts, unlike given empirical concepts, can be defined, which is what produces such familiar analytic claims as 'bachelors are unmarried'.

But-famously-empirical concepts do not exhaust the conceptual resources of Kant's system. Because human experience requires both intuitions and concepts, some concepts must be available prior to all experience, $;^{5}$ these are the a priori concepts, which again come in two varieties: given and constructed. A constructed a priori concept is another sort of concept that "I have invented" and therefore "can always define" (A729/B757). These turn up in mathematics:

Consequently, mathematics ... has definitions. For the object which it thinks it exhibits a priori in intuition, and this object certainly cannot contain either more or less than the concept, since it is through the definition that the concept of the object is given. (A729-30/B758-9) 
A mathematical concept can be thought of as a set of instructions for constructing a corresponding object in pure intuition, and as such, it can be defined simply by spelling out that recipe. Furthermore, since the construction process itself is constrained by the forms of intuition, many necessary properties of the resulting object are not contained in the definition (the set of instructions) alone, so some mathematical judgments come out synthetic.

The final variety of concepts consists of those that are given to us, rather than constructed by us, and given to us a priori, "by the nature of understanding," rather than empirically, "by experience" (A729/B757). Conspicuous among these pure concepts, of course, are the categories. Here Kant holds that

no concept given a priori, such as substance, cause, right, equity, etc., can, strictly speaking, be defined. . . . since the concept . . . may, as given, include many obscure representations, which we overlook in our analysis, although we are constantly making use of them in our application of the concept, the completeness of the analysis of my concept is always in doubt. . . Instead of the term, definition, I prefer to use the term exposition. (A728-9/B756-7)

In this realm beyond definitions, we are left with the original puzzle- "what determines that the truth of a given principle is or is not contained in the concepts involved?"- coupled with the new worry- "especially given that our analysis is 'always in doubt'?"

In Kant's eyes, the answer to this quandary lies in a contrast between a priori and empirical concepts. We've seen that empirical concepts like 'water' shift their content as science progresses; a priori concepts, by contrast, are not susceptible to modification on empirical grounds. But even if we grant that the content of given a priori concepts will not be subject to empirical adjustment, this fact hardly satisfies us on the point of what fixes their content in the first place. Beck describes the situation this way:

The rationalist tradition in which Kant wrote fixed many of the most important concepts by 'implicit' definition and common use or by nominal definitions that had become well established. Thus Kant could confidently decide that a given proposition is analytic without the necessity of referring to a 'rule book' of stipulative definitions. We, in a more conventionalistic period, are usually puzzled by some of his decisions, and can only feel that Kant and his contemporaries were committing what Whitehead called the 'fallacy of the perfect dictionary' - when the dictionary could not, in principle, exist for Kant at all. (Beck 44], p. 15)

In any case, it is indisputable that Kant held the content of given a priori concepts to be fixed, despite their being indefinable. And the fixed content of those concepts is what determines which claims involving them are analytic and which synthetic.

Against this backdrop, we can now ask where in the taxomony of concepts we might find the likes of 'or', 'all', 'is not', and 'if/then'. It is clear that logic, for Kant

abstracts from all content of knowledge, that is, from all relation of knowledge to the object, and considers only the logical form in the relation of any knowledge to other knowledge. (A55/B79)

In particular, this means that in pursuing logic 
we abstract from all empirical conditions under which our understanding is exercised, i.e., from the influence of the senses, the play of imagination, the laws of memory, the force of habit, inclination, etc. (A52-3/B77)

So it hardly seems that logical concepts could be empirical. Furthermore, logic

has nothing to do with the origin of knowledge, but only considers representations, be they originally a priori in ourselves or only empirically given, according to the laws which the understanding employs when, in thinking, it relates them to one another. It deals therefore only with that form which the understanding is able to impart to the representations, from whatever source they may have arisen. (A56/B80)

So logic cannot be concerned with the peculiarities of constructions in pure intuition, as in the study of constructed a priori concepts. ${ }^{6}$ The only bin left for 'or', 'some', and so on, is that of given a priori concepts, that of the categories.

The trouble with this conclusion, from the Kantian perspective, is that the table of categories is intended-notoriously - as a complete and exhaustive listing of the pure concepts of the understanding, the a priori given concepts of the understanding; it leaves no extra room for our hypothesized logical concepts. This means that 'all' and 'if/then' and the rest cannot be regarded as concepts of any sort in the Kantian scheme, and ipso facto that no truth can be 'contained in' these concepts. At this point, it is hard to retain the hope that logical truth might be classified as analytic on any sort of conceptual criterion. ${ }^{7}$

But all is not lost: this circuitous inquiry has brought us within hailing distance of an explicit Kantian theme on the nature of logic. We have seen that logical concepts, if there were such, would be a priori and given, akin to the categories. The categories, we know, are the pure concepts that the understanding must use in order to have any experience at all, in order to make any empirical judgments. Logic, according to Kant,

contains the absolutely necessary rules of thought without which there can be no employment whatsoever of the understanding. (A52/B76)

So the logical forms and the categories are closely related; our only error was in thinking both were concepts. Instead, logic concerns "the form of thought in general" (A131/B170); the logical notions are not concepts necessary for all judgment, but the forms necessary for combining concepts to produce judgments. From this point of view, our simple logical truths are not analytic, because they are not true by virtue of the content of concepts; rather, they are true by virtue of the structure of judgment.

But, for all the apparent generality here, Kant is actually speaking of a particular variety of understanding, a particular variety of judgment, namely, those of the discursive intellect; when he says that logic concerns "the form of thought in general," he adds in parentheses "that is, of discursive knowledge" (ibid.). So he is actually saying that logical notions are the various ways in which a discursive intellect can form judgments, that logical truths are true by virtue of the structure of discursive judgments. Let's see what can be made of this idea.

3 Laws of the discursive intellect In the previous section, we started with what seemed the appropriate classification from Kant's theory of judgments-analytic a 
priori-and tried to fit logic inside. This time, I propose to start from the other direction, to begin with Kant's characterization of logic and see where that leads us. The most general characterization, as we have seen, is that logic is the study of the necessary rules of a discursive intellect. So the first step is to ask, What is this discursive intellect?

In pursuit of this question, consider first the contrast between an intuitionwhich "relates immediately to the object and is single"-and a concept-which "refers to it mediately by measure of a feature [or features] which several things may have in common" (A320/B377). For human cognizers, intuitions and concepts arise from two distinct faculties - the sensibility and the understanding, respectively — and these faculties are profoundly dissimilar:

If the receptivity of our mind, its power of receiving representations in so far as it is in any wise affected, is to be entitled sensibility, then the mind's power of producing representations from itself, the spontaneity of knowledge, should be called the understanding. (A51/B75)

Our sensibility is passively receptive; even insofar as it contributes the forms of sensibility — space and time - it does so automatically, without the spontaneous activity characteristic of the understanding in its contribution of concepts. Both faculties are required for knowledge:

neither concepts without an intuition in some way corresponding to them, nor intuition without concepts, can yield knowledge. . . . Without sensibility no object would be given to us, without understanding no object would be thought. Thoughts without content are empty, intuitions without concepts are blind. (A50-1/B74-5)

Because concepts are always involved, that knowledge will be indirect:

Since no representation, save when it is an intuition, is in immediate relation to an object, no concept is ever related to an object immediately, but to some other representation of it, be that other representation an intuition, or itself a concept. Judgment is therefore the mediate knowledge of an object, that is, the representation of a representation of it. (A68/B93)

This is the feature that characterizes the discursive intellect:

the knowledge yielded by understanding, or at least by the human understanding [is] by means of concepts, and so is . . . discursive. (A68/B93)

Any intellect that gains knowledge only mediately, by means of concepts, will count as discursive.

To clarify the notion of a discursive intellect, Kant considers two contrasting cases. The first is an intellect whose intuition is spontaneous rather than receptive:

a power of complete spontaneity of intuition would be a cognitive power different from, and wholly independent of, sensibility. ([9], p. 406)

A cognizer with such a faculty would not be passively affected; rather, it would produce its intuitions from itself:

as, for example, a divine understanding which should not represent to itself given objects, but through whose representation the objects should themselves be given or produced. (B145) 
Such an intuition is 'original', that is, "such as can itself give us the existence of its object," and "so far as we can judge, can belong only to the primordial being" (B72). An intellect with a spontaneous (as opposed to receptive) intuition, Kant calls an intuitive (as opposed to discursive) intellect. ${ }^{8}$ Such an intellect would know objects directly - having created them-and would have knowledge of them that is unmediated by concepts.

On the other extreme from the intuitive intellect lies another foil for the discursive intellect. This second contrasting case appears in a letter from Kant to Hertz written as the outlines of the Critique were just beginning to take shape. ${ }^{9}$ There Kant first raises his characteristic question about the elements of our knowledge that originate in us rather than in things:

if such intellectual representations depend on our inner activity, whence comes the agreement that they are supposed to have with objects? (12], p. 72)

Kant had argued, in his Inaugural Dissertation, that space and time are forms of sensibility, but only recently

I noticed that I still lacked something essential... . In my dissertation I was content to explain the nature of intellectual representations in a merely negative way, namely, to state that they were not modifications of the soul brought about by the object. However, I silently passed over the further question of how a representation that refers to an object without being in any way affected by it can be possible. (ibid., pp. 71-72)

In hindsight, we see Kant on the verge of his Copernican revolution. In this context, he contrasts our human form of cognition with two distinct alternatives.

The first of the two is the 'intellectus archetypi', a term which he continues to use well after the Critique as a synonym for the 'intuitive intellect' discussed above (e.g., in [9], p. 408); the second is the 'intellectus ectypi'. 'Intellectus ectypi' eventually comes to be used as a synonym for 'discursive intellect' (e.g., ibid.), but at this early stage, it represents a second contrast case for human cognition.

To see how, consider the original question: How is the representation grounded in the represented? Of the intuitive intellect, Kant writes:

if that in us which we call 'representation' were active with regard to the object, that is, if the object itself were created by the representation (as when divine cognitions are conceived as archetypes of things), the conformity of these representations to their objects could be understood. (12], p. 71)

But there is a second possibility:

If a representation is only a way in which the subject is affected by the object, then it is easy to see how the representation is in conformity with the object, namely as an effect in accord with its cause, and it is easy to see how this modification of our mind can represent something, that is, have an object. (ibid.)

This is the intellectus ectypi, 'which would derive data for its logical procedure from the sensuous intuition of things', in other words, what we might call an empirical intellect. Such an intellect would gain knowledge directly from sensory experience; it, like the intuitive intellect, enjoys unmediated knowledge. The Kantian problem only arises for an intellect, which 
is not the cause of the object ... nor is the object the cause of the intellectual representations in the mind. (ibid.)

In this case, it is hard to see how the intellectual parts of the representation can correspond to the object, and according to Kant, this case is ours: the case of the discursive intellect. ${ }^{10}$ His answer, of course, is the famous Copernican Revolution and the doctrine of transcendental idealism: objects must conform to our forms of intuition and our categories because these help constitute the world we experience.

Given these characterizations of the various types of intellect, our question becomes: How is it that a discursive intellect in particular is governed by logic? The answer runs through some daunting Kantian terrain; fortunately a quick sketch will be enough for our purposes.

As we have seen, the discursive intellect has two faculties, sensibility and understanding. The sensibility provides unmediated intuitions of objects, but these intuitions do not create their objects (as they would for an intuitive intellect) nor do they reveal the objects as they are in themselves (as they would for an empirical intellect). Instead, the sensibility organizes a posteriori 'matter' - the rush and flux of unprocessed sense experience-using a priori 'forms' to produce 'appearances' (see, e.g., A19-20/B34). For us humans, these forms are space and time, but another discursive intellect could have different forms. It must have some forms, though, if it is discursive rather than empirical.

But this output of the sensibility is still short of discursive knowledge, because the spontaneous understanding and its concepts are not involved. All the work the understanding does is accomplished by one means: synthesis (see, e.g., B129-130). The understanding synthesizes various spatiotemporal intuitions into the representation of a single thing; it synthesizes various features that objects might have into a concept; it synthesizes various objects by bringing them under a single concept. The fundamental feature of the understanding that empowers it to do all this synthesizing is the transcendental unity of apperception (B136-7), which is Kant's offputting name for the unity of consciousness. ${ }^{11}$ Finally, when the transcendental unity of apperception manages to synthesize intuitions and concepts into knowledge of an object, this is called the "objective unity of apperception"- the most basic function of the discursive understanding (B141). ${ }^{12}$

Even granting all this, we might still wonder what this has to do with logic. Fortunately, the answer is within reach; it is declared as a section heading:

The logical form of all judgments consists in the objective unity of the apperception of the concepts which they contain. (B140)

Kant's idea is that the required objective unity can be achieved in a number of ways, following a number of patterns, and these patterns are precisely the logical forms of judgment listed in the famous Table of Judgments at the beginning of the Metaphysical Deduction: subject/predicate, if/then, disjunction, and on so (A70/B95). In other words, Kant claims that any discursive intellect, in bringing intuitions and concepts together so as to produce knowledge of objects, ${ }^{13}$ must employ just these forms of judgment. To extrapolate only slightly, one might go on to claim that the structure of these forms of judgment is what makes our examples into logical truths. This is why a discursive intellect is bound by the laws of logic. 
Now this must seem rather sudden, and not just because the story is so irresponsibly compressed. Even if we are willing to grant Kant his views on the identification of the discursive intellect, the explication of synthesis, and the role the unity of apperception, we might well balk at this last step: the stark claim that these and only these are the forms of judgment of any discursive intellect. This claim, famously, acts as a premise to the Metaphysical Deduction of the Categories: Kant argues that each form of judgment in the Table of Judgments corresponds to a pure (= a priori and given) concept of the understanding, so that the correct and complete table of forms of judgments yields a correct and complete table of the categories. (For example, in order to form an objective judgment in subject/predicate form, one must use the category of object with properties; in order to form an objective judgment in if/then form, one must use the category of ground and consequent; and so on. $)^{14}$ The complaint that Kant has not established his premise - that the Table of Judgments itself is correct and complete-goes all the way back to Fichte and Hegel.

For our purposes, of course, the Metaphysical Deduction is less important than its premise. We would like to know why a discursive intellect must judge according to these and only these forms; this would help us understand how logical truth is grounded in discursivity. Commentators disagree on what Kant intended here and on what he achieved, ${ }^{15}$ but so far as I know, the only major interpreter who holds that the Table of Judgments can be derived from the structure of the discursive intellect is Reich. ${ }^{16}$

Working from Kant's admonition that our identification of the categories must proceed "according to a single principle" (A67/B92), Reich focuses on Kant's discussion of synthesis. Kant remarks that to synthesize is to unify, but that this unity is not the category of unity, because

all categories are grounded in logical functions of judgment, and in these functions combination, and therefore unity of given concepts, is already thought. Thus the category already presupposes combination. (B131)

He concludes:

We therefore look yet higher for this unity ... namely in that which itself contains the grounds for the unity of diverse concepts in judgment, and therefore of the possibility of the understanding, even as regards its logical employment. (ibid., emphasis added)

We know this higher unity is the objective unity of apperception, and Kant soon makes this explicit:

The synthetic unity of apperception is therefore that highest point, to which we must ascribe all employment of the understanding, even the whole of logic.... The principle of apperception is the highest principle in the whole sphere of human knowledge. (B134-5, emphasis added)

Eventually, this 'highest point' is incorporated into Kant's account of judgment as "nothing but the manner in which given modes of knowledge are brought to the objective unity of apperception" (B141). This 'highest point' is the single principle on which Reich hopes to found his logic. ${ }^{17}$

Unfortunately, I must report that I have been unable to see how Reich's derivation of the forms of judgment from the objective unity of apperception is supposed to 
work. ${ }^{18}$ Of course, unless there is some oddly specific flaw in the notion of judgment involved, we can't (given our contemporary knowledge of logic) expect a derivation that purports to establish the correctness and completeness of Kant's table to be wholly convincing. Still, for the purposes of this examination of Kant's views, I propose to accept a basically Reichian understanding of how that view is structured: in particular, I propose we grant a necessary connection from the nature of discursive judgment to the objective unity of apperception to the Table of Judgments; in other words, I propose we grant that every discursive intellect must use the forms present in Kant's Table of Judgments in order to make objective judgments. ${ }^{19}$ Granting this, I think we can find in Reich's treatment some understanding of how the Table of Judgments is supposed to produce logical truths of the garden variety illustrated in our chosen samples.

The key is the observation that all synthesis is accomplished according to rules. This means, for example, that the concept of an object, which unifies many spatiotemporal intuitions as intuitions of a single thing, is or acts as a rule:

It is only when we have thus produced synthetic unity in the manifold of intuition that we are in a position to say that we know the object. But this unity is impossible if the intuition cannot be generated in accordance with a rule . . . a concept is always, as regards its form, something universal which serves as a rule. (A105-6)

Furthermore, the logical forms of judgment, which unify intuitions and concepts into judgments, are themselves rules: ${ }^{20}$
We have already defined the understanding in various different ways: as a spon- taneity of knowledge (in distinction from the receptivity of sensibility), as a power of thought, as a faculty of concepts, or again of judgments. All these definitions, when they are adequately understood, are identical. We may now characterise it as the faculty of rules. (A126)

The understanding is the faculty of judgments, these judgments have certain logical forms, and these logical forms are rules for synthesizing. In addition, Kant seems to think that a judgment formed according to a given rule itself embodies that rule.

So, for example, ${ }^{21}$ the categorical form of judgment unites the concepts 'oak' and 'tree' so that the first is a condition for the second, that is, the concept 'oak' synthesizes a manifold of intuitions, establishes reference to objects, and the judgment synthesizes these objects under the concept 'tree'. The resulting judgment-'all oaks are trees' - is then a rule that takes the subject as a condition for the predicate; the statement 'this is an oak' brings a particular oak under the condition of that rule; the conclusion - 'this is a tree' - results when the rule is applied (A304/B360-361, A330/B386-7). A similar story can be told for hypothetical syllogisms, and with some loss of plausibility, for disjunctive syllogisms. The upshot is that the logical must, for Kant, is the must of rule-following. ${ }^{22}$

In sum then, the account goes like this: a discursive intellect employs concepts; it has a receptive intuition and a spontaneous understanding. That spontaneous understanding works by synthesizing, and the ground of all synthesis is in the unity of apperception. In order to judge, the understanding must be capable of an objective unity of apperception, and that in turn means that it must employ certain logical forms. 
These logical forms, regarded as rules, yield logical truths like our examples. And this is more or less what Kant says:

logic has nothing to do with the possibility of knowledge in regard to its content, but merely with its form insofar as it is discursive knowledge. ([14], p. 244)

Logical truth is grounded in the structure of the discursive intellect; the logical must is the must of rule-following.

Notice that logic, on this account, is not purely descriptive. Individual discursive intellects such as ourselves can be led astray by a variety of empirical factors:

the influence of the senses, the play of imagination, the laws of memory, the force of habit, inclination, etc., and . . . all sources of prejudice. (A53/B77)

The study of these factors is the province of 'applied' logic, which

is directed to the rules of the employment of understanding under the subjective empirical conditions dealt with by psychology. (ibid.)

Logic itself "abstract[s] from all empirical conditions under which our understanding is exercised" and "has to do, therefore, only with principles a priori" (ibid.). Logic is not psychology; logic is normative.

On the epistemological side, Kant often remarks that logic is a priori, ${ }^{23}$ but he says little else. Given that logical truths arise out of the structure of our understanding, the process by which we come to believe them must be similar to that by which we come to believe (particular instances of) the synthetic principles of the pure understanding. In ordinary circumstances, perhaps it is enough to say that they are selfevidently necessary or universal. ${ }^{24}$ After we have grasped the basics of transcendental philosophy, we come to understand how and why it is that they are known a priori.

4 Analytic/synthetic revisited This seems to me a fairly Kantian account of logic; let's now consider how it connects back to the question of analyticity. The analytic/synthetic distinction as we've been treating it so far characterizes analyticity in formal terms - predicate concept contained in the concept of the subject—and a judgment is characterized as synthetic simply when it is not analytic. Against this, there are hints that Kant did not regard the distinction as a logical one (A154/B193, [15], 2a; [14], p. 244), and given the overall project of the Critique, we might well expect 'synthetic' rather than 'analytic' to be the fundamental notion of the two. In reply to critics, Kant does in fact take this approach:

this expounds with all necessary detail the principle of synthetic judgments in general, which follows necessarily from their definition, viz., that they are only possible under the condition that an intuition underlies the concept of their subject, which, if the judgments are empirical, is empirical, and if they are synthetic judgments a priori, is a pure intuition a priori. (14], p. 241, Kant's emphasis)

Synthetic judgments, on this reading, are those which refer to objects of intuition through their subject concepts and make assertions about them using their predicate concepts. ${ }^{25}$ We can generalize beyond subject/predicate judgments by counting as synthetic any judgment whose truth depends essentially on intuitive reference to objects. $^{26}$ 
Given this positive notion of what it is to be synthetic, we could proceed as before and characterize a judgment as analytic if and only if it is not synthetic, but I think it is more illuminating to stick with the two positive renderings: a judgment is analytic if its truth depends only on the concepts involved; a judgment is synthetic if its truth depends essentially on intuitive reference to objects. In a slogan: conceptual vs. intuitive.

The surprising result of this exercise is that logical truth falls between the stools. We've seen that logical truth is not conceptual: the concepts it would have to rest upon are logical (all, is, not, or, if/then), these must be given a priori, but the Table of Categories gives a complete list of such concepts. On the other hand, we've also seen that for Kant, logic deals with the form, not the content of thought, so it can hardly depend essentially on the intuitions that supply that content. Thus logical truth is neither analytic nor synthetic when these notions are understood in their respective positive senses.

The significance of this point becomes clear when we recall the teachings of transcendental idealism: because the world of experience is partly constituted by contributions from us, we can know a priori that the world we experience will conform to those contributions, but this a priori knowledge applies only to the world as experienced, not to the world as it is in itself. In particular, since space and time are the a priori forms of intuition, we can know a priori that everything we experience will be spatiotemporal, but

if the subject, or even only the subjective constitution of the sense in general, be removed, the whole constitution and all the relations of objects in space and time, nay space and time themselves, would vanish. (A42/B59)

So the synthetic a priori truths of mathematics are true only of the experience of a discursive intellect with human forms of intuition, not of the world as it is in itself.

The situation is somewhat more complex for the contributions of the pure understanding. We've seen that simply because it judges as it does, every discursive intellect, regardless of the details of its particular a priori forms of intuition, must employ the pure concepts of the understanding. We might be tempted to conclude that the familiar principles of the pure understanding, like the law of cause and effect, are true of the experience of every discursive intellect, ${ }^{27}$ but this would be wrong. The case of cause and effect can serve as an illustrative example of why this is so: the pure concept involved here is that of ground and consequent, which in turn underwrites the hypothetical judgment form (if/then), but that pure concept bears no relation to the world of spatiotemporal experience until it is schematized; schemata form the link between the pure concepts and the objects of spatiotemporal experience. Only when it is schematized does the pure concept of ground and consequent yield a concept of cause and effect that can be applied to things in the world of experience. ${ }^{28}$ So the understanding does generate synthetic a priori truths about the world of experience, but only after its pure concepts have been schematized, and this process depends essentially on the details of our forms of intuition. Thus, despite the fact that every discursive intellect must employ the pure concepts, only a discursive intellect with our forms of intuition will be bound by the corresponding synthetic a priori principles. The law of causation is like the truths of mathematics: true of the experience of discursive intellects with our forms of intuition, but not of the world as it is in itself. 
Where does this leave logical truth? Again, it's not merely conceptual; it is not generated straightforwardly by the concepts involved, like a garden-variety analytic truth. On the other hand, as we've repeated many times, logical truth abstracts from the details of experience, so it cannot depend on the particular forms of human intuition. What it depends on - again a familiar refrain - is the structure of any discursive intellect, which puts it on a par with the categories, before they are schematized. This means that while analytic truths are simply true judgments about concepts, and synthetic a priori truths are true only of the world of any human experience, logical truth falls in between: it is true of the world of any discursive experience. ${ }^{29}$ To paraphrase the passage from Kant that was just quoted:

if the discursive subject, or even only the subjective constitution of the discursive understanding in general, be removed, the whole constitution and all the logical relations of objects, nay logic itself, would vanish.

Logic, for Kant, is transcendentally ideal, in the sense that it reflects features of the world as it is (partly) constituted by our cognitive machinery, rather than features of the world as it is in itself. But it is not transcendentally ideal in so strong a sense as the synthetic a priori principles found in mathematics and the analogies of experience, because it depends only on the discursive part of our cognitive machinery, not on our particular forms of intuition. For future reference, let us call this 'weak' transcendental ideality. ${ }^{30}$

5 Analytic/synthetic de-emphasized This seems to me a plausibly Kantian view of logical truth: it isn't the sort of purely conceptual truth we normally classify as analytic; it isn't the sort of intuitive truth we normally classify as synthetic; it is (weakly) transcendentally ideal. In fact, the view seems to me an intriguing one in its own right, one I would like to examine briefly from the point of view of a contemporary naturalist, but before moving on to that speculative project, we need to make one last observation from within the Kantian framework.

Our route to this position in Sections 24 rests in part on the idea that logical truth is not analytic because it is not conceptual. This in turn rests on a line of thought that runs from the completeness of the Table of Judgments to the completeness of the Table of Categories: if logical notions were concepts, they would have to be pure concepts of the understanding, and as such, they would have to appear in the Table; but they don't. Here, for once, we rely on Kant's dubious claim that the Table of Judgments is complete, but we've granted many other dubious or opaque Kantianisms along the way, so this does not trouble me unduly. Considerably more troubling is Allison's argument that the forms of judgment and the pure categories are one and the same ${ }^{31}$ if so, logical notions are concepts after all, and the obstacle to the analytic status of logical truth is removed. While I'm unpersuaded by Allison's argument for this conclusion, I hesitate to disagree on such a fundamental point with the very scholar whose influential work is largely responsible for my own dim understanding of the Critique. But most troubling of all, it is hard to see what matter of principle hangs on our supposed distinction between concepts necessary for objective judgment (the categories) and forms necessary for objective judgment (the logical forms). Without some understanding of a substantive difference here, it's hard to see why we should not exercise a reasonable amount of generosity and expand the notion of analytic to 
include logical truths, just as we expanded it earlier to include truths of other than subject/predicate form. ${ }^{32}$

I think there is something important behind these worries, and the best way I know of getting at it is to explore the consequences of Allison's identification of the pure categories with the logical forms. On that view, since categories are concepts, so are the logical forms of judgment. In examples like ours-if it's either red or green and it's not red, then it must be green - the logical concepts must be represented by the logical words-if/then, either, and, is, is not-and this judgment is true by virtue of those concepts. In other words, it is analytic, after all, and our previous worries on this score were misplaced. My claim is that despite this, the general outline of our Kantian position, summarized at the beginning of this section, survives intact, and that understanding why this is so will lead to an improvement in precisely those details of the position that have been bothering us here.

To see this, recall our Kantian taxonomy of concepts. For both varieties of constructed concepts-empirical and a priori-explicit definitions are available, and these explicit definitions make for easy analytic truths: 'All bachelors are unmarried' and 'All squares have four sides'. This is the style of analytic truth that's familiar to us: the trivial definitional judgment. In the case of empirical given concepts, such as 'water', we are interested in the empirical stuff, not the concept; we give tentative definitions and let science guide us on how to modify them in the light of experiment. Here again we get analytic truths, but they are shifting and insignificant as well as trivially definitional in the sense just described. But the case of a priori given concepts, like the categories, is very different. Here we cannot give definitions at all; rather we grope towards 'expositions' of preexisting concepts that we understand only dimly, and we can never be sure if we have succeeded. ${ }^{33}$

Now consider an analytic judgment whose truth depends on a given a priori concept. This will certainly not be a trivial, definitional truth, because every element of the exposition of such a concept is a hard-won analysis of something fixed and preexisting. Though its truth is "contained in the concept," this is not the transparent containment with which 'unmarried' is contained in 'bachelor' or 'four sidedness' in 'square'. In some ways, this nontrivial brand of analytic judgment more closely resembles synthetic truths about empirical given concepts such as 'water' than it does definitional truths about constructed concepts, be they empirical or a priori. Granted, the synthetic truth about water requires appeal to intuition-that's what makes it synthetic-while the analytic truth about a given a priori concept requires only the tools of philosophical analysis, but both are nontrivial truths about things not of our manufacture, in contrast to the empty definitional character of other analytic truths.

My point is this. Even if we grant Allison's reading - that is, even if we regard the logical forms of judgment as a priori given concepts, take logical truths to depend only on the logical concepts involved, and so classify them as analytic-there still remains a gulf between the type of judgment involved in those logical truths and the trivial, definitional judgments most commonly associated with the term 'analytic'. In other words, there will still be three brands of judgments - trivially analytic, nontrivially analytic, and synthetic — with logical truth falling in the middle.

Furthermore, given that the concepts that underlie logical truth are precisely the 
concepts necessary for any discursive intellect, our previous conclusion about the (weak) transcendentally ideal status of logical truth remains secure. Whereas the definitional analytic truths merely repeat what is contained in explicit definitions, the logical truths reflect contentful information about the structure of discursive thought, and as such, they apply only to experience that is so structured, that is, to the experience of discursive knowers. Thus my first conclusion, that the general outlines of the view are preserved: logic isn't the sort of trivial definitional truth we normally classify as analytic; it is not the sort of intuitive truth we normally classify as synthetic; it is (weakly) transcendentally ideal.

But this is not to say that nothing has changed. The discussion of Sections 24 concludes that logical truth differs from analytic truth in that the latter, not the former, concerns concepts; on this reading, nontrivial analytic truths about given a priori concepts would be classified with the trivial analytic truths, both in contrast with logical truths, which are not analytic at all. The present discussion concludes instead that logical truth and nontrivial analytic truths about other a priori concepts differ from trivial analytic truths, because they give us contentful information about things that are given to us rather than trifling information about things we have constructed or about our use of words. This new way of classifying seems considerably more illuminating.

Even if we do not, in the end, follow Allison in his identification of the logical forms with the categories, even if we continue to hold that logical truth is not conceptual, it is clear that the truths of logic are much more like hard-won truths about given a priori concepts than either of these are like the trivial analytic truths: both of the former give contentful information about the world of experience, without being synthetic; both are (weakly) transcendentally ideal. Thus my second conclusion: wherever we decide it is best to draw the distinction between analytic and synthetic, and for whatever reasons, the salient distinction for the purposes of this paper is the one that puts trivial, definitional truths on one side, and logical truths and conceptual truths about given a priori concepts on the other.

6 Undoing the Copernican Revolution To sum up, I have argued that the attempt to understand logical truth as analytic faces unexpected obstacles, which may explain why Kant seems reluctant to so classify it. Most often, he characterizes logical truths as the necessary rules of the discursive intellect, and I have tried to explain why he would say this and what it means. Logical truths become judgments about the structure of discursive cognition, and as such, true of the experience of any such intellect; they appear to us self-evident, and our transcendental analysis shows them to be a priori; the force of the logical must comes from the rigidity of rule-following. The most compelling result of this analysis is that logical truth, for Kant, is neither trivially conceptual nor synthetic, neither true by definition nor true only of the experience of a human knower. It falls in between: true of the experience of any discursive knower, whatever its forms of intuition. This seems to me a subtle position worthy of serious contemplation.

Let me conclude here, as promised, with a sketchy look at the figure this Kantian position might cut when viewed from the perspective of a contemporary naturalist. To see how this goes, we need to step back and situate our discussion of 
logic within the grand scheme of Kant's critical philosophy. The goal there is to explain how we have a priori knowledge of the world, and the method is transcendental analysis; we examine the workings of our intellect and conclude that the a priori elements of our knowledge are due to the nonempirical contributions we make to the constitution of the world we experience. As we all know, these nonempirical elements turn out to be the forms of intuition and the categories.

None of this makes sense unless we distinguish sharply between transcendental philosophy and ordinary empirical inquiry into the structure of human cognition, the sort of thing once attempted by "the celebrated Locke" (Aix) and now undertaken by a broad range of neuropsychologists and cognitive scientists. These empirical inquiries, carried out within the context of our broader scientific world view, may tell us a good deal about how humans experience the world, but they do not tell us how the world we experience must be. For that style of conclusion, we must operate, not at the scientific level, but at the transcendental level, where we hope to isolate the conditions necessary for the experience of any discursive intellect with our forms of intuition. Here we are concerned, not with the foibles of the empirical ego-which may or may not accurately reflect the world-but with the necessary structures of the transcendental ego. From this perspective, the conditions we uncover are supposed to apply necessarily to any world an intellect of our type can experience, so that we can know their truth a priori, in advance of that experience.

Now the term 'naturalism' has been used in a variety of ways in recent philosophical discussions, but one recurrent theme is the rejection of extra-scientific perspectives such as that of Kant's transcendental philosophy. ${ }^{34}$ If we want a naturalistic version of Kant's position on logic, we must begin by trading the transcendental inquiry for the ordinary empirical one, the transcendental ego for the ordinary empirical one. After this sacrifice, it is reasonable to ask if anything remains of our Kantian account of logic.

Kant's idea is that our judging is bound by logic because we are judgers of a certain sort: discursive, as opposed to intuitive or empirical. Of course, we have little real understanding of what intuitive or empirical cognition would be like-for Kant, it is actually impossible for us to conceive these things-but I suspect contemporary science would second some version of the Kantian notion that certain elements of our experience are not present in our purely sensory inputs. It even seems reasonable to suppose that some version of spatiotemporality and some features such as 'physical object' and 'dependency of one event on another' are conceptual additions. So perhaps the naturalist could argue that the empirical ego is in fact structured along loosely discursive lines.

From here, Reich would argue that we must judge in subject/predicate and if/then forms, and Kant would argue (in the Metaphysical Deduction) that we must, therefore, use concepts such as object/properties and ground/consequent. ${ }^{35}$ Though the naturalist may well be skeptical of these a priori arguments, she might nevertheless marshall scientific evidence to the effect that we do in fact judge in these ways and use concepts like these. If the naturalist were to reach this point, then a naturalized, neo-Kantian account of logic would present itself as an option. The position would go something like this: anyone judging in these ways, using these concepts is bound by the laws of logic; these laws appear self-evident because they are rooted in our most 
fundamental conceptualizations; and (if the Kantian idea that judgments are rules can also be carried over) the source of the logic must is the force of rule-following.

But - and this is the important point—even if all this could be filled in, the naturalistic neo-Kantian would still not have answers to the big questions we started out with. Where the Kantian's transcendental analysis tells us how we must judge the world, and hence, how the world we experience must be, the naturalistic neo-Kantian only tells us how we, in fact, judge the world, not how the world we experience must be. As is well known, the progress of science since Kant has not been congenial to his views of how our world must be; one way to read the lesson of these developments is that Kant failed to realize that the scientific method could ultimately teach us that the world isn't quite as our most basic cognitive machinery would have it. ${ }^{36}$ From this perspective, our empirical analysis of the workings of the empirical ego need not square with our informed scientific theory of how the world really is.

So even if our empirical analysis of ourselves as cognizers determines that we are discursive intellects more or less of the type Kant describes, and even if it follows from this that our judging is bound by the laws of logic, and so on, it remains an open question whether or not those laws of logic reflect objective features of the world. Even if we conclude that the laws of logic bind anyone who conceptualizes in terms of subject/predicate and if/then, object/property, and ground/consequent, we do not know if such conceptualization is veridical. For the naturalist, this is a scientific question like any other. We would need to check, perhaps from case to case, whether or not our fundamental modes of judging correspond to real regularities in the world. ${ }^{37}$ We might occasionally find, as perhaps we have found in quantum mechanics, that the world is not so cooperative, and that we have to be somewhat careful of the concepts we use and the inferences we draw. ${ }^{38}$

With regard to the big questions, this leaves us with the following: the laws of logic bind our thinking as soon as we judge in terms of subject/predicate and if/then, object/properties and ground/consequent; the laws of logic are valid for the world insofar as it admits of being conceptualized in these ways. ${ }^{39}$ Epistemologically, our neo-Kantian naturalist would say, with Kant, that the truths of logic appear to us selfevident because they spring from our most fundamental modes of conceptualization, but where Kant ensures the correctness of these modes with transcendental analysis, the naturalist must argue that they correspond to the way the world is, must engage in empirical inquiry. And finally, if there were a viable naturalized version of Kant's analysis of logical forms as rules, the naturalized neo-Kantian could follow the orthodox Kantian in tracing the logical must to rule-following.

Notice that this naturalistic view would preserve some of the attractions of its Kantian ancestor. On the one hand, logic would not be trivially definitional. On the other hand-assuming our naturalist is able to preserve something of the distinction between the forms of intuition on one side, and the forms of judgment and unschematized categories on the other-the dependence of logic on empirical evidence would be limited to the most schematic features of our experience. But all this is sheer speculation. What I hope to have established here is that the Kantian framework produces a richer account of logical truth than might have been expected, and that the contemporary naturalist may have something valuable to learn from that account. 
Acknowledgments My thanks to Kurt Mosser for early conversations, to Lara Denis for helpful comments on an earlier draft, and to the participants at the Boolos Memorial Conference at Notre Dame in April 1998, especially Karl Ameriks, Charles Parsons, and Sally Sedgwick. I am also grateful to Sedgwick, again, and especially to Kyle Stanford, for their careful attention to the penultimate draft.

\section{NOTES}

1. I use 'logic' without modifier for what Kant calls 'general logic', as opposed to 'transcendental logic'. See A50-57/B74-82.

2. That is, the syllogistic. Also, Kant denies that $A=A$ is a 'principle', while principles are the concern of logic (A53/B77).

3. It might be suggested that Kant refrains from applying 'analytic' to logic because his logic consists of inferences, not judgments. Possibly, but it would seem that same scruple should apply to 'a priori'. Furthermore, he is happy to apply the modality 'apodeictic' to a judgment that 'expresses a logical necessity' (A76/B101; 11], p. 766). And (as Charles Parsons pointed out in discussion), it seems that even if Kant concentrates on logical inference, he still owes an account of statements like 'either it's raining or it's not raining'. I prefer not to focus on this example because Kant's views on categorical and hypothetical judgments seem to me more accessible and plausible than his account of disjunctive judgments, but Parsons's point remains even if my sample judgments are dismissed as fundamentally inferential.

4. Jäsche (13], §36) puts this symbolically in his version of Kant's logic: "An example of an analytic proposition is, To everything $x$, to which the concept of body $(a+b)$ belongs, belongs also extension $(b)$. An example of a synthetic proposition is, To everything $x$, to which the concept body $(a+b)$ belongs, belongs also attraction (c)."

5. Cf. Allison 11, pp. 64-65, and [2], pp. 116-17.

6. That is the province of 'transcendental logic', with which our 'general logic' is contrasted. See note 1.

7. Section 5 reopens this question.

8. See B68, B135, B138-39, B159, and B307. See also Allison's account of the historical role of 'theocentric model of knowledge' ([2], pp. 19-25, and footnote 2, pp. 340-41).

9. See Beck [3] and Allison 11], pp. 57-59, for discussion of this letter.

10. See Allison [2], pp. 65-66, and 340-41, footnote 2, for a similar characterization of the alternatives to the discursive intellect.

11. Against Hume, Kant holds that all my representations are held together as mine (see B131-132, 134) — they are thus synthesized—but against Descartes, he also holds that this does not add up to awareness of a self (see B404). See Kitcher [16, Chapters 4 and 7.

12. At B135 and B138-39, Kant reminds us that these conclusions are peculiar to the discursive intellect.

13. In fact, the act of judgment is fundamental for Kant; the other syntheses-of intuitions, features, concepts, and so on-all take place at once, in the act of judging.

14. See Allison [2], Chapter 6. Cf. Melnick [19], pp. 37-42. 
15. For example, Hegel held that Kant's table is "taken merely from observation and so only empirically treated." (Translated in Reich [20], p. 2. For a summary of opinion, see Ellington 77, footnote 24, pp. 148-49. See also Beck [5, pp. xxii-xiii.) But despite Kant's stated admiration for ancient logicians (Bviii), and despite his claim to agreement with standard logics (A70/B96), the table actually contains innovations of his own, apparently added for transcendental rather than logical reasons (that is, to get the Metaphysical Deduction to work). (Kant describes these departures directly after giving the Table (A71-76/B96-101). For a history of the development of the table, see de Vleeschauwer [6], pp. 75-82.) Furthermore, Kant insists that his method of isolating the categories differs from Aristotle's in that his table "has not arisen rhapsodically" (A81/B106).

16. In 201. Ellington 7 reports that when he read Reich's book, "It was like walking into a brightly lighted room" (p. 150), echoing Goethe's remark on reading the Critique. (In Kant and the Capacity to Judge [17, Longuenesse argues that the connection between the Table of Judgments and the categories is central to the main arguments of the Critique; I regret that I was unable to take account of her discussion in the preparation of this paper.)

17. See Reich [20], Chapters 5 and 6. Ellington 7 , pp. 148-73, provides his own rendition of the derivation, following Reich's lead.

18. I record a couple of my puzzlements. In the derivation of the categorical form, Reich argues: since judgment has only concepts available to it, and a concept, as an analytic unity, does not refer to objects, judgment can only do this by means of a condition; that condition is another concept; therefore, the discursive understanding must employ the categorical form of judgment ([20], pp. 49-50; cf. Ellington [7], pp. 151-52). I wonder: if one concept cannot manage to refer, how does adding a second concept help? In the derivation of necessary judgments, Reich argues: given that the discursive understanding must employ the disjunctive form of judgment, we find the "either . . . or" is also a necessary judgment ([20], pp. 55-56; cf. Ellington [7], pp. 158-59). I wonder: Cannot disjuctions be contingent as well as necessary?

19. For most purposes here, it isn't essential that the Table be complete; we could leave open the possibility that some discursive intellect might use other forms in addition to those in the Table. (In fact, most of what follows only depends on the assumption that every discursive intellect uses at least the categorical, hypothetical and disjunctive forms.) The exception is the argument of Section 2 (repeated in Section 4 ) that logical notions like 'all' and 'if/then' are not concepts in the Kantian scheme. This argument is bypassed in Section 5 .

20. Reich [20], p. 72, notes that A127 and B143 say the same thing except that 'rule' has been replaced by 'logical form of judgment'. See also A299/B356 and A302/B359: "Understanding may be regarded as a faculty which secures the unity of appearances by means of rules."

21. This isn't spelled out in Reich or Kant, so I'm guessing.

22. We needn't hold Kant responsible to late Wittgensteinian worries on this head.

23. See, e.g., A53/B77; A131/B170; 13], p. 15; 11], p. 693.

24. Cf. Tonelli 21], p. 51.

25. Of course, analytic judgments are true of objects, too, but their truth is independent of that reference; they 'abstract' from content. 
26. This account of syntheticity connects the notion with synthesis, concept formation and judgment, the schematism and other central Kantian themes in subtle and illuminating ways detailed by Allison ([1], pp. 60-75).

27. For the record, notice that this is a decidedly un-Kantian use of the word 'experience'. For Kant, ordinary experience is generated when a logical form of judgment synthesizes sensible intuitions (which are themselves the work of the spatiotemporal forms of intuition) together with concepts, and in particular, with schematized categories. What I am imagining is a discursive intellect, who must necessarily share our logical forms of judgment and (hence) our pure categories, but who may have different forms of intuition. Such an intellect will have something that seems to me to deserve the name 'experience', that is, experience constituted by the logical forms of judgment, intuitions generated by that intellect's own forms of intuition, and the categories schematized appropriately to those forms. This is what I mean when I speak of the experience of a discursive knower.

28. Note the three levels: the logical form (if/then), the pure category (ground/consequent), the schematized category (cause/effect).

29. See note 27.

30. Here again, I am somewhat abusing Kantian terminology (see also note 27). Kant reserves the term 'transcendentally ideal' for space and time, the forms of intuition. But the idea is that space and time are not features of the world as it is in itself, but of the world as it is experienced by discursive knowers with our forms of intuition. My suggestion is that logical truths do not reflect features of the world as it is in itself, but of the world as it is experienced by any discursive knower, regardless of its forms of intuition. (It is important to insist that the forms of judgment and the resulting pure categories are involved in the constitution of ordinary experience itself, both for us and for any other discursive knower.) This seems to me a legitimate form of transcendental ideality.

31. See Allison [2], pp. 125-26. Notice that the three levels of note 28 are now two: logical form/pure category (if/then $=$ ground/consequent), schematized category (cause/effect).

32. This way of putting the point was suggested to me by Kyle Stanford.

33. "Since the definitions are analyses of given concepts, they presuppose the prior presence of the concepts, although in a confused state" (A730). "Analytic definitions [that is, definitions produced by analysis, as opposed to definitions of constructed concepts] . . may err in many ways, either through introducing characteristics which do not really belong to the concept, or by lacking that completeness which is the essential feature of a definition. The latter defect is due to the fact that we can never be quite certain of the completeness of the analysis" (A732/B760).

34. I explore this idea in greater detail in 18 .

35. I concentrate on these two contributions of the pure understanding: the logical forms subject/predicate and if/then, which (according to Kant) correspond to the pure categories object/property and ground/consequent, whose schematized versions are spatiotemporal object with properties and cause/effect. The complete details of Kant's Tables of Judgments and Categories would almost certainly have to be altered in an upto-date naturalized account, so I focus in these sketchy remarks on two that might be expected to survive.

36. Gödel takes a position along these lines in 8 .

37. Notice that the conclusion that logic is objectively valid does not require that the discursive way of conceptualizing is the only correct way; it only requires that it be among the correct ways, that it track some real structure in the world. 
38. Of course, some observers insist that we need a 'new logic' for quantum mechanics. I don't mean to advocate this move. I only point out that our simple-minded attempts to understand particles as objects with properties have not worked out. One standard solution is to stop talking about objects with properties and start talking about the quantum state, a mathematical representation. Serious work in the philosophy of quantum mechanics begins well after this point.

39. This view can be modernized one step further by trading the question "Do our fundamental modes of cognition reflect features of the world?" for the question "Does our language have the right sort of semantic features?" With this change, the naturalistic neo-Kantianism described here begins to resemble a contemporary view laid out in Wilson 22] and [23]. To quote from the final section of the latter: "if we are guaranteed that the sets and other ingredients needed to supply truth-conditions are well defined within the setting at hand, then first-order reasoning over this language can be trusted."

\section{REFERENCES}

[1] Allison, H., The Kant-Eberhard Controversy, Johns Hopkins University Press, Baltimore, 1973. 6.6.6

[2] Allison, H., Kant's Transcendental Idealism, Yale University Press, New Haven, 1983. 6,6,6,6,6

[3] Beck, L. W., "Kant's letter to Marcus Hertz, February 21, 1772," pp. 54-60, in Studies in the Philosophy of Kant, Bobbs-Merrill, Indianapolis, 1965. 6

[4] Beck, L. W., "Can Kant's synthetic judgments be made analytic?," pp. 3-22, in Kant: A Collection of Critical Essays, edited by R. P. Wolff, University of Notre Dame Press, Notre Dame, 1968. 2.2

[5] Beck, L.W., "Foreword," pp. xi-xx in K. Reich, The Completeness of Kant's Table of Judgments, translated by J. Kneller and M. Losonsky, Stanford University Press, Stanford, 1992.

[6] de Vleeschauwer, H.-J., The Development of Kantian Thought: the History of a Doctrine, translated by A. R. C. Duncan, Thomas Nelson and Sons, London, 1962. (The 1939 French edition of this book is a condensation of Vleeschauwer's La Déduction transcendentale dans l'oeuvre de Kant, 3 volumes, Paris, Leroux, 1934-37.) 6

[7] Ellington, J., "The unity of Kant's thought in his philosophy of corporeal nature," pp. 135-219, in Philosophy of Material Nature, Hackett, Indianapolis, 1985. 6.6.6.6. 6

[8] Gödel, K., "Some observations about the relationship between theory of relativity and Kantian philosophy," pp. 230-59 in Collected Works, vol. 3, edited by S. Feferman et al., Oxford University Press, Oxford, 1995.MR 96f:01043 6

[9] Kant, I., Critique of Judgment, translated by W. S. Pluhar, Hackett, Indianapolis, 1987. 3.3

[10] Kant, I., Critique of Pure Reason, translated by N. K. Smith, St. Martin's Press, New York, 1965.

[11] Kant, I., “The Dohna-Wundlacken Logic,” pp. 425-516 in Lectures on Logic, translated by J. M. Young, Cambridge University Press, Cambridge, 1992. MR 95m:01022 2,6, 6 
[12] Kant, I., "To Marcus Hertz, February 21, 1772," pp. 70-76, in Kant: Philosophical Correspondence, translated and edited by A. Zweig, University of Chicago Press, Chicago, 1967. 3,3

[13] Kant, I., “The Jäsche Logic," pp. 517-640 in Lectures on Logic, translated by J. M. Young, Cambridge University Press, Cambridge, 1992.MR 95m:01022 2, 6,6

[14] Kant, I., "On a discovery according to which any new critique of pure reason has been made superfluous by an earlier one," pp. 105-60 in H. Allison, The Kant-Eberhard Controversy, Johns Hopkins University Press, Baltimore, 1973. 3,4,4,4

[15] Kant, I., Prolegomena to any Future Metaphysics, translated by L. W. Beck, BobbsMerrill, Indianapolis, 1950. 4

[16] Kitcher, P., Kant's Transcendental Psychology, Oxford University Press, New York, 1990. 6

[17] Longuenesse, B., Kant and the Capacity to Judge: Sensibility and Discursivity in the Transcendental Analytic of the Critique of Pure Reason, Princeton University Press, Princeton, 1997. 6

[18] Maddy, P., "Naturalism and the a priori," forthcoming in New Essays on the A Priori, edited by P. Boghossian and C. Peacocke, Oxford Univeristy Press, Oxford. 6

[19] Melnick, A., Kant's Analogies of Experience, University of Chicago Press, Chicago, 1973. 6

[20] Reich, K., The Completeness of Kant's Table of Judgments, translated by J. Kneller and M. Losonsky, Stanford University Press, Stanford, 1992. 6, 6, 6, 6, 6, 6, 6

[21] Tonelli, G., Kant's Critique of Pure Reason within the Tradition of Modern Logic, edited by D. H. Chandler, George Olms, Zurich, 1994. 6

[22] Wilson, M., "Can we trust logical form?," Journal of Philosophy, vol. 91 (1994), pp. 519-44. MR 12994756

[23] Wilson, M., "Inference and correlational truth," pp. 371-95 in Circularity, Definition and Truth, edited by A. Chapuis and A. Gupta, Indian Council of Philosophical Research, New Delhi, 2000. 6

Department of Logic and Philosophy of Science

University of California, Irvine

Irvine CA 92697-5100

email: pimaddy@uci.edu 